Published in final edited form as:

ACS Appl Mater Interfaces. 2016 August 17; 8(32): 20540-20548. doi:10.1021/acsami.6b04679.

\title{
A Self-Assembling Injectable Biomimetic Microenvironment Encourages Retinal Ganglion Cell Axon Extension in Vitro
}

\author{
Melissa R. Laughter ${ }^{\dagger}$, David A. Ammar ${ }^{\ddagger}$, James R. BardilI ${ }^{\dagger}$, Brisa Pena ${ }^{\dagger}$, Malik Y. Kahook ${ }^{\ddagger}$, \\ David J. Lee ${ }^{\dagger}$, and Daewon Park ${ }^{\star}, \dagger$ \\ tDepartment of Bioengineering, University of Colorado Denver Anschutz Medical Campus, \\ Aurora, Colorado 80045, United States \\ ‡Department of Ophthalmology, University of Colorado Denver Anschutz Medical Campus, \\ Aurora, Colorado 80045, United States
}

\begin{abstract}
Sensory-somatic nervous system neurons, such as retinal ganglion cells (RGCs), are typically thought to be incapable of regenerating. However, it is now known that these cells may be stimulated to regenerate by providing them with a growth permissive environment. We have engineered an injectable microenvironment designed to provide growth-stimulating cues for RGC culture. Upon gelation, this injectable material not only self-assembles into laminar sheets, similar to retinal organization, but also possesses a storage modulus comparable to that of retinal tissue. Primary rat RGCs were grown, stained, and imaged in this three-dimensional scaffold. We were able to show that RGCs grown in this retina-like structure exhibited characteristic long, prominent axons. In addition, RGCs showed a consistent increase in average axon length and neurite-bearing ratio over the 7 day culture period, indicating this scaffold is capable of supporting substantial RGC axon extension.
\end{abstract}

\section{Graphical Abstract}

\footnotetext{
*Corresponding Author: daewon.park@ucdenver.edu. Author Contributions

M.R.L. performed all aspects of the study, including polymer synthesis, RGC isolation, 3D staining, imaging, and image analysis. D.A.A. assisted with crucial elements of the RGC isolation and provided guidance to make this work successful. J.R.B. performed the RGC isolation and GPC analysis. B.P. assisted with the 3D scaffold staining. D.J.L. assisted with the RGC isolation. M.Y.K. conceived of the study and provided means for conducting this work. D.P. conceived the study and provided the means and direction for the synthesis and characterization of this polymer system.

The authors declare no competing financial interest.

Supporting Information

The Supporting Information is available free of charge on the ACS Publications website at DOI: 10.1021/acsami.6b04679.

Full reaction schematic, GPC polymer analysis, FT-IR polymer analysis, HPLC polymer analysis, figures of RGCs growing in the PSHU-PNIPAAm control, and rheological study of the loss modulus (PDF)
} 


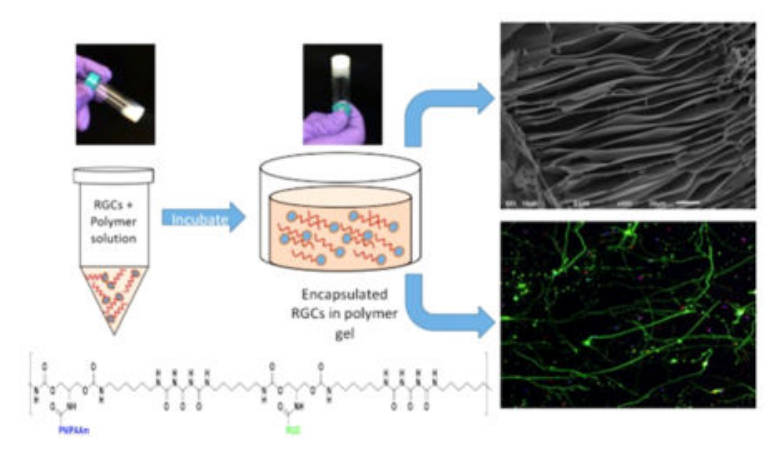

\section{Keywords}

biomimetic; retinal ganglion cells; reverse thermal gel; self-assembling; 3D scaffold

\section{INTRODUCTION}

Glaucoma, among other optic neuropathies, leads to the neurodegeneration of retinal ganglion cells (RGCs), the projection neurons located in the retina with axons extending through the optic nerve. ${ }^{1}$ These cells play a crucial role in sight by transmitting visual information from the bipolar, amacrine, and interplexiform cells of the retina to the visual cortex of the brain. ${ }^{2}$ Because of the inability of these cells to regenerate under the normal human disease condition, the loss of these cells is permanent. ${ }^{3}$ Additionally, clinical therapies for glaucoma are currently limited to treatments that prevent or limit further damage to the RGCs. ${ }^{4,5}$ Future interventions that seek to regain or improve visual function must not only include mechanisms for RGC neuroprotection but also methods that facilitate the survival and axon regeneration of damaged RGCs and eventually methods to replace dead RGCs.

It was previously believed that RGCs, like many central nervous system neurons, do not possess the ability to regenerate following injury or death. However, it is now known that the limited regeneration of axonal regrowth of these cells is possible but inhibited because of the injured microenvironment (myelin-associated molecules), ${ }^{6-8}$ scar formation, ${ }^{9,10}$ and lack of passage across a lesion. ${ }^{11-13}$ Therefore, the regenerative capacity of RGCs may be stimulated by creating an alternate extracellular microenvironment that will instead activate RGC growth, maintain RGC viability, and counteract the inhibitory signals of the injured nerve. ${ }^{14}$ To alter the fate of damaged RGCs, the cells must be encapsulated in a growth permissive microenvironment, protected from the diseased environment, presented with cell binding molecules, and exposed to appropriate mechanical properties to induce and cue growth.

Here, we have developed an injectable biomimetic three-dimensional (3D) scaffold with mechanical and morphological properties similar to those of native retinal tissue. The first component of this polymer system is a previously described, highly functionalizable backbone aimed at mimicking a native extracellular matrix (ECM). ${ }^{15}$ The second component of this polymer system is the small peptide arginine-glycine-aspartic acid (RGD), an 
integrin/cell binding motif found in many components of the ECM. It has been well established that cellular adhesions made through RGD-integrin binding can promote cell survival, cell spreading, proliferation, and neurite extension. ${ }^{15}$ In this study, the peptide sequence GRGDS was used instead of RGD to preserve the integrity of the entire RGD binding motif. Studies have shown that the RGD tripeptide has little effect on cell attachment; however, surrounding the RGD motif with flanking amino acids according to the natural sequence (GRGDS) can preserve the activity of this integrin binding motif. ${ }^{16}$ Lastly, we modified this polymer system with poly ( $N$-isopropylacrylamide) (PNI-PAAm) to allow for an injectable cellular scaffold. PNIPAAm, a thermosensitive water-soluble homopolymer, has garnered a lot of attention in the biomedical field. ${ }^{17-20}$ This polymer has been shown to exhibit a sharp, reversible sol-gel transition point at $32{ }^{\circ} \mathrm{C}$, suffciently above room temperature and suffciently below body temperature making it extremely useful for many biomedical applications. ${ }^{21}$ Following synthesis and characterization of this polymer system, we investigated the 3D growth of RGCs cultured within this polymer scaffold. The results of this work provide insight into the complex mechanical and chemical environment that supports RGC growth in three dimensions and could have a direct application in cellular replacement therapies for the treatment of RGC-associated ocular neurodegeneration and other neurodegenerative diseases.

\section{MATERIALS AND METHODS}

\section{Materials}

N-BOC-Serinol, urea, hexamethylene diisocyanate (HDI), anhydrous chloroform, and anhydrous $N, N$-dimethylformamide (DMF), $N$-isopropylacrylamide (NIPAAm), and 4,4'azobis(4-cyanovaleric acid) (ACA) were purchased from Sigma-Aldrich (St. Louis, MO). $N$ [3-(Dimethylamino)propyl]- $\mathrm{N}$-ethylcarbodiimide hydrochloride (EDC), $\mathrm{N}$ -

hydroxysuccinimide (NHS), and trifluoroacetic acid (TFA) were purchased from Alfa Aesar (Ward Hill, MA). Anhydrous diethyl ether was purchased from Fisher Scientific (Pittsburgh, PA). Anhydrous dichloromethane (DCM) was purchased from J. T. Baker (Phillipsburg, NJ). The pentapeptide Gly-Arg-Gly-Asp-Ser (GRGDS) was purchased from Biomatik (Wilmington, DE). Dialysis tubing (Spectra/Por) was obtained from Spectrum Laboratories (Houston, TX).

\section{Equipment}

Gel permeation chromatography (GPC) was recorded on a Viscotek GPC Max instrument with a 270 Dual Detector with right angle light scattering (RALS) and a VE 3580 refractive index (RI) detector from Malvern Instruments (Houston, TX). Each sample's numberaverage molecular mass $\left(M_{\mathrm{n}}\right)$ and weight-average molecular mass $\left(M_{\mathrm{w}}\right)$ were calculated using OmniSEC version 5.02. Fourier transform infrared (FT-IR) spectra were recorded on a Nicolet 6700 instrument (Thermo Fisher Scientific, Waltham, MA) using polyethylenewindowed equipment. High-performance liquid chromatography (HPLC) was conducted on an Agilent Zorbax 300SB C8 HPLC system. The analytical column size is $2.1 \mathrm{~mm} \times 150$ $\mathrm{mm}$ with a flow rate of $0.3 \mathrm{~mL} / \mathrm{min}$. The following buffers were used: (1) $0.2 \% \mathrm{TFA} /$ water and (2) $0.18 \%$ TFA/AcN (acetonitrile). A 6 min isocratic run was used first and then $6 \mathrm{~min}$ at a linear gradient $1 \% \mathrm{~B} / \mathrm{min}$. Detection was performed at $210 \mathrm{~nm}$. All in vitro cell 
morphologies were examined on a Nikon DIAPHOT 300 camera equipped with a CCD camera (SPOT RT 2.3.0, Diagnostic Instruments) using SPOT Advanced software for post hoc analysis. Polymer morphology was imaged using a JEOL (Peabody, MA) JSAM-6010la analytical scanning electron microscope. Rheological measurements were performed on a stress-controlled rheometer (Rheostress Haake RS 150) using a cone-and-plate geometry (angle of $1^{\circ}$, diameter of $60 \mathrm{~mm}$ ) and a solvent trap to prevent evaporation of the polymer solution. Confocal images were collected using a Nikon Eclipse Ti C2 LUN-A microscope (Nikon, Tokyo, Japan) equipped with two C2-DU3 high-sensitivity PMT detectors, four diode lasers $(405,488,561$, and $640 \mathrm{~nm})$, and a motorized microscope stage with three-axis navigation $(X, Y$, and $Z$ ) controlled by the NIS-Elements software package. Laser and software settings were kept constant between specimens to allow for comparison of different image acquisitions.

\section{Synthesis of Poly(serinol hexamethylene urea) (PSHU)}

PSHU was synthesized as previously described. ${ }^{15}$ In brief, a 2:1:1 (molar ratio) HDI/NBOC-Serinol/urea mixture was dissolved in anhydrous DMF $(5 \mathrm{~mL})$ and reacted for 7 days at $90{ }^{\circ} \mathrm{C}$. The product mixture was then purified using rotary evaporation followed by precipitation in excess anhydrous ether. The product, PSHU, was lyophilized at $-45^{\circ} \mathrm{C}$ for $24 \mathrm{~h}$ and stored at room temperature.

\section{Functionalization of PSHU with PNIPAAm and RGD}

Synthesis of PNIPAAm followed by conjugation of PNIPAAm to the PSHU backbone was completed as previously described. ${ }^{22}$ In short, NIPAAm $(44.19 \mathrm{mmol})$ and ACA $(0.22$ mmol) were dissolved in $25 \mathrm{~mL}$ of dry methanol and purged with nitrogen for $30 \mathrm{~min}$. The reaction was then allowed to proceed for $3 \mathrm{~h}$ at $68^{\circ} \mathrm{C}$. The product mixture was then precipitated once and washed twice in hot water $\left(60^{\circ} \mathrm{C}\right)$. The final product was purified further via dialysis [molecular weight cutoff (MWCO) of $3500 \mathrm{Da}$ ] and lyophilized for storage. To conjugate PNIPAAm-COOH to PSHU, BOC groups from the PSHU backbone were removed using a strong acid mixture [1:1 (v/v) DCM/ TFA] to expose functionalizable free amines. Next, PNIPAAm-COOH $(0.01 \mathrm{mmol})$ was reacted with EDC $(0.048 \mathrm{mmol})$ and NHS $(0.048 \mathrm{mmol})$ for $24 \mathrm{~h}$ to activate the carboxylic acid group; $100 \mathrm{mg}$ of the deprotected PSHU was then added to the activated PNIPAAm and allowed to react for $24 \mathrm{~h}$. This product mixture was precipitated in anhydrous diethyl ether twice and dialyzed (MWCO of 12000 Da) for 3 days until it was lyophilized for storage. Next, RGD (0.125 g, $0.25 \mathrm{mmol})$, EDC $(0.143 \mathrm{~g}, 0.75 \mathrm{mmol})$, and NHS $(0.86 \mathrm{~g}, 0.75 \mathrm{mmol})$ were dissolved in ultrapure water. This solution was reacted at room temperature for $2 \mathrm{~h}$. PSHU-PNIPAAm $(0.10 \mathrm{~g})$ was dissolved in ultrapure water, added dropwise to the activated RGD solution, and reacted for $24 \mathrm{~h}$ at room temperature, protected from light. After $24 \mathrm{~h}$, the reaction mixture was placed in dialysis tubing (MWCO of 3500) and dialyzed against $1 \mathrm{~L}$ of ultrapure water for $24 \mathrm{~h}$, with one water change. After dialysis, the solution was freeze-dried, resulting in a white, flaky precipitate.

\section{Gel Permeation Chromatography (GPC)}

GPC (Malvern Instruments) was used to determine the molecular weight distribution of the synthesized copolymers. Analysis was performed on each sample using a $100 \mu \mathrm{L}$ injection 
into a single Viscotek D6000M column and a 270 Dual Detector with right angle light scattering with DMF as the system solvent. The column and detector temperatures were kept constant at $45{ }^{\circ} \mathrm{C}$. The instrument was calibrated with polystyrene standards (MW of $105000, \mathrm{~d} n / \mathrm{d} c$ of $0.185 \mathrm{~mL} / \mathrm{g})$.

\section{Solution to Gel Phase Transition}

A lower critical solution temperature (LCST) was used to analyze the gelling properties of the thermally reversible injectable scaffold; $1 \%(\mathrm{wt} / \mathrm{v})$ PSHU-PNIPAAm and PSHUPNIPAAm-RGD were loaded in a temperature-controlled UV/visible spectrophotometer. The transmittance through the polymer solution at $480 \mathrm{~nm}$ was monitored as the temperature was increased from 15 to $45^{\circ} \mathrm{C}$. Gelation activity was indicated by an increase in opaqueness and therefore a decrease in transmittance.

\section{Scaffold Morphology}

Polymer solutions $(2.5,5$, and $10 \%)$ were prepared in ultrapure water and allowed to gel at $37^{\circ} \mathrm{C}$ for $15 \mathrm{~min}$. The gelled samples were then frozen quickly using liquid nitrogen, making them solid enough to cut in half and expose the center structure. The samples were then rapidly transferred to a freeze-dryer for $24 \mathrm{~h}\left(-48^{\circ} \mathrm{C}, 38 \times 10^{-3}\right)$. Liquid nitrogen was used to freeze the samples rapidly $(\sim 3 \mathrm{~s})$ to avoid degelling of the polymer and preserve its 3D structure. The samples were then sputter coated with gold for $30 \mathrm{~s}$, and the cross section of the gel was analyzed using scanning electron microscopy (SEM).

\section{Mechanical Properties}

First, polymers (PSHU-PNIPAAm-RGD and PSHU-PNIPAAm) were dissolved in RGC media at concentrations of $2.5,5$, and $10 \mathrm{wt} \%$. Temperature sweep tests composed of heating ramps (at $\left.5{ }^{\circ} \mathrm{C} / \mathrm{min}\right)$ were conducted at a constant frequency $(1 \mathrm{~Hz})$ and stress $(0.05$ Pa) between 25 and $45^{\circ} \mathrm{C}$.

\section{Animal Procedures}

All animal experiments were performed in accordance with procedures approved by the Institutional Animal Care and Use Committee (IACUC) at the University of Colorado Denver Anschutz Medical Campus. All experiments were performed in accordance with IACUC guidelines and regulations. A total of two breeding pairs (male Wistar rats, 350-400 $\mathrm{g}$, and female Wistar rats, 250-300 g) were required to complete this project. These animals were used to spawn rat pups by housing one male and one female rat per cage. Once the rat pups reach postnatal day 5-7, the pups were euthanized by prolonged exposure to $\mathrm{CO}_{2}(\sim 50$ $\mathrm{min}$ ) followed by a secondary form of euthanasia (decapitation).

\section{Retinal Ganglion Cell Isolation}

RGCs were purified from rat pups (postnatal day 5-7) as these cells show higher survival rates following the separation process. To begin, eyes were carefully enucleated and transferred to a Petri dish filled with D-PBS. Using a dissecting microscope, a small incision was made along the anterior part of the eye (behind the lens and cornea). Tweezers were inserted into the small incision, and the eye was carefully pulled along this incision line to 
maintain the integrity of the retina. At this point, the retina was peeled away from the sclera and was moved with a transfer pipet to a $15 \mathrm{~mL}$ tube. The dissected retinas were then dissociated using the Neural Tissue Dissociation Kit for Postnatal Neurons from Miltenyi Biotec per the manufacturer's instructions. Following this, the RGCs were purified using the Retinal Ganglion Cell Isolation Kit from Miltenyi Biotec per the manufacturer's instructions. The isolated cells containing mostly RGCs were then resuspended in prewarmed RGC growth medium containing MACS NeuroMedium (130-093-570), NeuroBrew-21 (1:50 dilution, 130-093-566), sodium pyruvate (Sigma, $1 \mathrm{mM}$ ), BDNF (Peprotech, $25 \mathrm{ng} / \mathrm{mL}$ ), CNTF (Peprotech, $10 \mathrm{ng} / \mathrm{mL}$ ), $N$-acetylcysteine $(50 \mu \mathrm{g} / \mathrm{mL})$, insulin (Sigma, $5 \mu \mathrm{g} / \mathrm{mL}$ ), Forskolin (Sigma, $10 \mu \mathrm{M}$ ), glutamine $(2 \mathrm{mM})$, triiodothyronin (40 ng/ $\mathrm{mL})$, streptomycin sulfate $(100 \mu \mathrm{g} / \mathrm{mL})$, and penicillin (100 units $/ \mathrm{mL})$. Cells were then plated on PDL-Laminin-coated coverslips (data not shown) or seeded in 3D polymer scaffolds. Three separate RGC isolations were completed on three different rat pup litters.

\section{D Culture of Retinal Ganglion Cells}

RGCs $\left(8 \times 10^{3}\right)$ were suspended in a solution of $5 \mathrm{wt} \%$ PSHU-PNIPAAm-RGD or $5 \mathrm{wt} \%$ PSHU-PNIPAAm in complete medium; $50 \mu \mathrm{L}$ of the cell suspension in the polymer solutions was pipetted into each $35 \mathrm{~mm}$ glass bottom dish (MatTek, Ashland, MA) (Figure 1) and placed in a $37{ }^{\circ} \mathrm{C}$ incubator for 10 min to allow polymer gelation and RGC encapsulation. After incubation, $1 \mathrm{~mL}$ of warm, RGC medium was added to the culture dish, using a hot plate set at $37{ }^{\circ} \mathrm{C}$ to maintain gel stability when the dish is removed from the incubator. Cells were cultured for 3, 5, and 7 days, with daily changes of media.

\section{Live/Dead Assay}

Cells cultured within the 3D scaffold were washed three times with warm PBS $\left(37^{\circ} \mathrm{C}\right)$. Following washing, the live/dead assay was used per the manufacturer's instructions. Briefly, the live/dead solution ( $250 \mu \mathrm{L}$ ) was added to the 3D culture dish and allowed to incubate for $15 \mathrm{~min}$. The solution was aspirated off, and the culture dish was washed again with warm PBS $\left(37^{\circ} \mathrm{C}\right)$ before imaging.

\section{Immunostaining within the 3D Scaffold}

Cells were immunostained while remaining encapsulated in the 3D polymer scaffold. It is important to note that all steps of the staining process were conducted at $37{ }^{\circ} \mathrm{C}$ to prevent degelling and disruption of the polymer sample. First, samples were washed twice with $1 \times$ PBS and fixed with $4 \%$ PFA in PBS for 15 min at $37{ }^{\circ} \mathrm{C}$. Next, samples were permeabilized with $1 \%$ Triton-X (in PBS) for 90 min, followed by a PBS wash overnight. Blocking buffer composed of $2 \%$ bovine serum albumin (BSA) in PBS was added to the cells for $90 \mathrm{~min}$. After being blocked, cells were incubated overnight with the first primary antibody Brn3a (1:200, prepared in blocking buffer). Cells were then washed with $1 \%$ Triton-X, three times for 3 min each. The secondary antibody, anti-goat Alexa 594 (1:500), was added to each sample and incubated for $45 \mathrm{~min}$. Cells were washed with PBS-Tween (0.002\% in PBS) for 3 min and washed twice with PBS, for 3 min each. Cells were then incubated with the second primary antibody $\beta$ III-tubulin (1:100, prepared in blocking buffer) overnight at $37^{\circ} \mathrm{C}$. Cells were then washed with $1 \%$ Triton-X, three times for 3 min each. The secondary antibody, anti-rabbit Alexa 488 (1:500), was added to each sample and incubated for $45 \mathrm{~min}$. 
Cells were washed with PBS-Tween (0.002\% in PBS) for 3 min and washed twice with PBS, for 3 min each. Hoechst 33342 (1:2000, in PBS), a DAPI stain, was added to each sample, and the mixtures were incubated for 5-10 min, followed by three washes in PBS, for 3 min each. RGCs were imaged within the polymer scaffold using fluorescence confocal microscopy.

\section{Analysis of Average Neurite Length, Average Branchpoint, and Neurite-Bearing Cells}

Using a $20 \times$ objective, $\mathrm{z}$-stack projections of $4 \mu \mathrm{m}$ thickness were sampled from three random visual fields in each sample. At least nine samples taken from three different RGC isolations were analyzed for each time point and for each polymer (PSHU-PNIPAAm-RGD and PSHU-PNIPAAm). The simple neurite tracer plugin from FIJI (Longair, Baker, and Armstrong, 2011) was used to analyze the length of each process. Each neurite was traced starting from the cell body extending out into the image frame. The total length of the neuritis was divided by the cell count determined using DAPI to obtain the average neurite length.

\section{Statistical Analysis}

Statistical significance among three or more data sets will be determined by analysis of variance (ANOVA), while the $t$ test will be used to compare significance between two groups. A $p$ value of $<0.05$ will be considered statistically significant.

\section{RESULTS}

\section{Polymer Scaffold Morphology and Mechanical Properties}

The complete reaction schematic of PSHU-PNIPAAm conjugated to RGD may be found in Figure S1. The molecular weight distribution of PSHU was determined by GPC. GPC analysis showed molecular weights for PSHU, a number-average molecular mass $\left(M_{\mathrm{n}}\right)$ of $1610 \mathrm{Da}$, a weight-average molecular mass $\left(M_{\mathrm{w}}\right)$ of $3354 \mathrm{Da}$, and a PI $\left(M_{\mathrm{w}} / M_{\mathrm{n}}\right)$ of 2.083 (Figures S2 and S3). FT-IR spectroscopy was used to confirm the conjugation of RGD to the polymer backbone by viewing the region of $1630-1680 \mathrm{~cm}^{-1}$ (Figure S4). This region is associated with the carbonyl groups found within the polymer backbone as well as the carbonyl groups found within peptide bonds of RGD. The wavenumbers correlated to the carbonyl groups of RGD are slightly lower than those of the carbonyl groups in the polymer backbone. In the PSHU-PNIPAAm-RGD spectrum, we can observe an obvious shift in this carbonyl peak toward the lower end of the spectrum, indicating the presence of carbonyl groups in the RGD peptide. High-performance liquid chromatography (HPLC) was also used to quantify the amount of GRGDS-COOH that was successfully conjugated to the free amine groups on the polymer backbone. A calibration curve was first constructed using known concentrations of GRGDS-COOH $(0.78-200 \mu \mathrm{g} / \mathrm{mL})$ (Figure S5). Each of these concentrations produced a corresponding HPLC peak area. Using the calculated area beneath the peaks and the corresponding calibration curve, we were able to determine the amount of RGD within each sample and thus the corresponding RGD conjugation efficiency. Results showed 93\% conjugation of RGD to the free amine groups on the polymer backbone. The lower critical solution temperature (LCST) refers to the temperature that determines the physical state of a thermogel and is therefore an extremely important 
characteristic for this application. ${ }^{23,24}$ PSHU-PNIPAAm-RGD exhibited a LCST and phase transition profile very similar to that of PSHU-PNIPAAm (Figure 2), remaining in solution state at temperatures below $32{ }^{\circ} \mathrm{C}$ and rapidly undergoing a phase transition to a physical gel upon reaching body temperature. These unique characteristics will allow PSHU-PNIPAAmRGD to be administered through a minimally invasive injection at the desired location.

SEM was used to investigate the morphology of the 3D polymer scaffold after gelation at body temperature. As shown in Figure 3, higher concentrations (5 and $10 \mathrm{wt} \%$ ) of both PSHU-PNIPAAm-RGD and PSHU-PNIPAAm assembled into a laminar sheet-like conformation upon gelling. However, at a low concentration ( $2.5 \mathrm{wt} \%)$, both polymer systems formed a heterogeneous structure, implying unstable gelling conditions. Rheology was used to assess the mechanical properties of the polymer scaffold as compared to native retinal tissue. Figure 4 shows the storage modulus $(G)$ plotted against increasing temperature. All six polymer samples showed a $G$ that was greater than the loss modulus $(G)$ (Figure S6), indicating the dominant elastic behavior of the polymer scaffold. ${ }^{25}$ The value for PSHU-PNIPAAm-RGD and PSHU-PNIPAAm both increased with increasing polymer concentration and temperature. In addition, the incorporation of RGD showed a slight increase in $G$ at all three polymer concentrations. Five weight percent polymer concentrations for both PSHU-PNIPAAm-RGD and PSHU-PNIPAAm were selected for all subsequent cell studies because these gel concentrations (1) formed a laminar structure similar to that of the optic nerve tissue and (2) led to mechanical properties more similar to those of retinal tissue than those at other concentrations. In addition, at polymer concentrations lower than $5 \mathrm{wt} \%$, the solid gel structure was not fully stable, causing deterioration of the gel in response to slight temperature changes making these lower concentrations not suitable for cell scaffolding.

\section{D Culture of RGCs in an Injectable Polymer Scaffold}

The first aim of this work was to determine how RGCs would behave once they were encapsulated in the 3D polymer scaffold. Following optimization and characterization of the injectable material, we were able to select the polymer system that was most similar to native retinal tissue and would likely support the growth and axon extension of RGCs. RGCs from rat pups postnatal day 5-7 were purified and seeded simply through mixing with the polymer solution. Once the cell/ polymer mixture was placed in the incubator, the cells became encapsulated in the 3D scaffold. Using confocal microscopy, we were able to visualize RGC axons growing in three dimensions throughout the scaffold. Figure 5 displays maximal intensity images from $200 \mu \mathrm{m}$ thick z-stacks with $4 \mu \mathrm{m}$ intervals. Cells grown in PSHU-PNIPAAm-RGD (5 wt \%) showed robust axon extension, whereas cells grown in PSHU-PNIPAAm (5 wt \%) showed minimal axon extension (Figure S7). RGCs grown on the PDL-Laminin-coated coverslips displayed a "starlike" morphology extending shorter axons in all directions (Figure 6). Furthermore, live/dead analysis of RGCs grown on the PDL-Laminin coverslips compared to RGCs grown within the polymer scaffold show decreased cell viability following 3 days in culture; however, cells grown within the polymer scaffold show increased viability for a minimum of 7 days in culture (Figure S8). PDLLaminin was chosen as a positive control as it is a commonly used coating for growing retinal ganglion cells, ${ }^{26,27}$ and the laminin possesses integrin binding motifs (RGD), 
providing a comparison between the RGD-conjugated 3D scaffold and two-dimensional coverslips. In contrast, RGCs in their native retinal environment typically extend fewer and longer axons in a unilateral direction. This morphology of RGCs in vivo is called laminar growth where neurons extend processes focusing in one plane and thus possess a more direct growth pattern to their final connections. ${ }^{28}$ Interestingly, the RGCs grown within the polymer scaffold presented a morphology similar to that of RGCs in vivo, ${ }^{28}$ showing a similar two-directional growth likely due to the sheet-like morphology of the scaffold. This morphology limits the RGCs from extending in all directions.

\section{Image Analysis of 3D RGC Cultures}

The average neurite length was determined by measuring the total length of all axons (in three dimensions) within a visual field and dividing this number by the total cell count within that field. Panels AC in Figure 7 show the image analysis process, where Figure 7A is the maximal intensity image of a visual field and Figure 7B shows the measured axon length in the $X-Y, X-Z$, and $Y-Z$ frames. Figure $7 \mathrm{C}$ graphs the average axon length versus culture period. We can see that there is a significant difference between the mean axon length on days 3 and $5(p<0.001)$ as well as a significant difference between days 5 and $7(p<0.01)$. The ratio of neurite-bearing cells was calculated by determining the number of neuritebearing cells per frame (only RGCs bearing neurites with a length greater than two cell bodies were counted) and dividing this number by the total cell count (determined by nuclear DAPI stain). Figure 7D shows the total cell count in a visual field, and Figure 7E is an example of a maximal intensity image used for counting neurite-bearing cells. From Figure 7F, we can see that there is no significant difference between the ratio of neuritebearing cells from day 3 to 5 or from day 5 to 7 ; however, there is a significant difference between the ratio of neurite-bearing cells from day 3 to $7(p<0.01)$.

\section{DISCUSSION}

Various optic neuropathies, such as glaucomatous and traumatic optic neuropathies, result in the death or damage of RGCs. ${ }^{1}$ Damage to these cells decreases or completely obstructs signal pathways responsible for sight. In addition, RGCs rarely regenerate under the normal disease condition, making early detection and prevention critical. However, treatments aimed at preventing further damage unfortunately do not account for lost RGCs. The ultimate goal for treating patients in the late stage of the disease process is cell replacement therapy. For cell replacement therapies to be successful, the transplanted cells must not only survive transplantation ${ }^{29-31}$ but also adopt the correct morphology and organization through instructive cues provided by their environment. ${ }^{32}$ Unfortunately, transplantations consisting solely of cells are hindered by a diseased microenvironment characterized by growthinhibitory signals. ${ }^{10,33}$ One method for addressing these restraints is through a cellular scaffold, engineered to act as a cell carrier and improve the fate and morphology of the implanted cells. We have designed a multicomponent biomaterial that can be injected into a heavily damaged environment and act as a bioactive replacement niche. The reverse thermal gelling property of this polymer system will allow simple mixing of the RGCs with the polymer at room temperature and encapsulation of the cells within the 3D polymer scaffold upon reaching physiological temperatures. Cells can then be stained and imaged within the 
scaffold to approximately the center of the gel $(250 \mu \mathrm{m})$ (Figure 1). Unlike two-dimensional (2D) systems, this injectable 3D scaffold is more attune to the cell-cell interactions, cellular organization, and microenvironment seen in native tissue. In three dimensions, cells can be fully encapsulated in a solid microenvironment rather than solely exposed to one flat $2 \mathrm{D}$ surface. ${ }^{34}$

Along with being injectable, this polymer system is functionalized with cell binding peptides to improve cellular localization and axon extension. For RGCs specifically, the L1 integrin binding molecule that contains the peptide sequence RGD was shown to be present in axonal regeneration of RGCs. ${ }^{35}$ Because integrins modulate how cells interact with their substrate, increasing the number of L1 binding sites (RGD) within the polymer scaffold could increase the level of cell adhesion, cell growth, and extension of axons within the 3D matrix. RGD was chemically conjugated to the polymer backbone, to provide a stable linkage capable of withstanding the cellular contractile forces and promoting strong cellular adhesion (Figure 8). ${ }^{36}$ In addition, we were able to alter the amount of RGD present by simply altering the concentration of the polymer. This provided a more facile and controllable polymer system compared to altering the conjugation of RGD to the backbone itself. This allowed us to retain the maximal conjugation of RGD to the polymer backbone. It was typically thought that incorporation of these adhesion proteins on polymeric materials altered only the biochemical environment and imparts no change to the mechanical properties of the material. ${ }^{37}$ However, it is now known that incorporating cell substrata (such as RGD) can alter the mechanical compliance of polymeric materials depending on the incorporation technique employed. ${ }^{38}$ Using this logic, chemically conjugating RGD to the polymeric backbone could not only provide cells with a secure adhesion site necessary for a strong attachment but also alter the polymer's mechanical properties to be more similar to those of native retinal tissue. ${ }^{38}$ Furthermore, this polymer system self-assembles into a morphology similar to that of retinal tissue. Retinal tissue has a laminar organization in which different cell types are layered within specific retinal strata. Similar to this laminar structure, upon forming a gel, this polymer system assembles into sheets. In addition, we were able to create a polymer system with a $G$ similar to that of retinal tissue. At a concentration of $5 \mathrm{wt} \%$, the polymer system possessed the laminar sheet-like morphology seen in the native tissue ${ }^{39}$ and had a $G$ of $200 \mathrm{~Pa}$ (Figure 4), which is comparable to the value of $100 \mathrm{~Pa}$ of retinal tissue, ${ }^{40}$ making this system the best choice for subsequent studies. Furthermore, unlike lower concentrations, the polymer concentration of $5 \mathrm{wt} \%$ provided a stable gel more suitable for cell scaffolding and in vitro cultures.

This work aimed to test the efficacy of this 3D scaffold through in vitro studies with RGCs. By studying the survival, axon extension, and morphology of the cells grown in this $3 \mathrm{D}$ scaffold, we can determine whether this polymer system is a good model for growing RGCs in vitro as well as a promising scaffold for use in cell replacement therapies. In their native environment, RGCs develop in a single monolayer with long axons extending horizontally toward a single point in the back of the eye, eventually joining together to form the optic nerve. However, current in vitro culture conditions (2D) have been able to produce only RGCs with short axons or axons extending in all directions. Although certain groups have been able to produce RGCs showing a unilateral morphology using 3D scaffolds, these studies have used an electrospun scaffold that requires implantation and were unable to seed 
cells directly within the scaffold. ${ }^{41}$ To provide a more suitable 3D culture and induce greater axon extension, we engineered a polymer system with properties similar to that of retinal tissue structure..$^{25,42}$ Retinal tissue is laminar in structure with RGC axons extending horizontally toward the optic cup. Therefore, recreating this sheet structure could provide topographical cues and, along with biomolecular cues of RGD, guide horizontal extension of RGC axons.

Collectively, we created a material that is similar to an RGC's native environment, which could induce the same morphology and axon extension seen in the retinal ganglion layer. Through the use of this retina-like scaffold, we were able to mimic a cell's native environment and provide improved RGC culture conditions in vitro. Culture of RGCs in this 3D polymer system exhibited long, prominent axons, similar to what is seen in the native retina ${ }^{26}$ (Figure 5). In addition, the average axon length and ratio of neurite-bearing cells increased steadily over the 7 day culture period (Figure 7).

\section{CONCLUSIONS}

We developed a 3D scaffold, providing both topographical and biochemical cues of a native retinal microenvironment, with great potential for RGC survival and extensive axon extension. We believe that this 3D polymer system could provide researchers with an improved model for in vitro RGC studies. This type of culture system could be utilized to investigate stratified structures, branching, and synaptogenesis in three dimensions while still preserving the appropriate cellular morphology. ${ }^{26}$ These results also show that this injectable scaffold could be promising for use in future cellular replacement studies aimed at treating optic neurodegenerative diseases.

\section{Supplementary Material}

Refer to Web version on PubMed Central for supplementary material.

\section{Acknowledgments}

This work was partially supported by National Institutes of Health Grants 1R21EY023711-01A1 and 1R21EY025333-01. Dr. Mark Petrash provided resources for staining and imaging the 3D scaffold. Dr. Kristi Anseth provided resources for performing the rheology study.

\section{References}

1. Almasieh M, Wilson AM, Morquette B, Cueva Vargas JL, Di Polo A. The Molecular Basis of Retinal Ganglion Cell Death in Glaucoma. Prog Retinal Eye Res. 2012; 31(2):152-181.

2. Lilley S, Robbins J. The Rat Retinal Ganglion Cell in Culture: An Accessible CNS Neurone. J Pharmacol Toxicol Methods. 2005; 51(3):209-220. [PubMed: 15862466]

3. So K, Yip HK. Regenerative Capacity of Retinal Ganglion Cells in Mammals. Vision Res. 1998; 38:1525-1535. [PubMed: 9667017]

4. Medeiros FA, Alencar LM, Zangwill LM, Bowd C, Sample P, Weinreb RN. Prediction of Functional Loss in Glaucoma From Progressive Optic Disc Damage. Arch Ophthalmol. 2016; 127(10):1250 1256.

5. Cantor L. Achieving Low Target Pressures With Today's Glaucoma Medications. Surv Ophthalmol. 2003; 48(2):S8-S16. [PubMed: 12852429] 
6. Magharious M, D'Onofrio PM, Hollander A, Zhu P, Chen J, Koeberle PD. Quantitative iTRAQ Analysis of Retinal Ganglion Cell Degeneration after Optic Nerve Crush. J Proteome Res. 2011; 10:3344-3362. [PubMed: 21627321]

7. Schwab ME, Chen MS, Huber AB, van der Haar ME, Frank M, Schnell L, Spillmann AA, Christ F. Nogo-A Is a Myelin-Associated Neurite Outgrowth Inhibitor and an Antigen for Monoclonal Antibody IN-1. Nature. 2000; 403:434-439. [PubMed: 10667796]

8. Filbin MT. Myelin-Associated Inhibitors of Axonal Regeneration in the Adult Mammalian CNS. Nat Rev Neurosci. 2003; 4(9):703-713. [PubMed: 12951563]

9. Windle F. Regeneration of Axons in the Vertebrate Nervous System. Physiol Rev. 1956; 36:427440. [PubMed: 13370344]

10. Silver J, Miller JH. Regeneration beyond the Glial Scar. Nat Rev Neurosci. 2004; 5(2):146-156. [PubMed: 14735117]

11. Pernet V, Schwab ME. Lost in the Jungle: New Hurdles for Optic Nerve Axon Regeneration. Trends Neurosci. 2014; 37(7):381-387. [PubMed: 24874558]

12. Cho BP, Song DY, Sugama S, Shin DH, Shimizu Y, Kim SS, Kim YS, Joh TH. Pathological Dynamics of Activated Microglia Following Medial Forebrain Bundle Transection. Glia. 2006; 53(1):92-102. [PubMed: 16206155]

13. Lazarov-Spiegler O, Rapalino O, Agranov G, Schwartz M. Restricted Inflammatory Reaction in the CNS: A Key Impediment to Axonal Regeneration? Mol Med Today. 1998; 4:337-342. [PubMed: 9755452]

14. Benowitz L, Yuquin Y. Optic Nerve Regeneration. Arch Ophthalmol. 2010; 128(8):1059-1064. [PubMed: 20697009]

15. Yun D, Lee YM, Laughter MR, Freed CR, Park D. Substantial Differentiation of Human Neural Stem Cells Into Motor Neurons on a Biomimetic Polyurea. Macromol Biosci. 2015; 15:12061211. [PubMed: 26033933]

16. Pierschbacher MD, Ruoslahti E. Influence of Stereochemistry of the Sequence Arg-Gly-Asp-Xaa on Binding Specificity in Cell Adhesion. J Biol Chem. 1987; 262:17294-17298. [PubMed: 3693352]

17. Kador KE, Goldberg JL. Scaffolds and Stem Cells: Delivery of Cell Transplants for Retinal Degenerations. Expert Rev Ophthalmol. 2012; 7(5):459-470. [PubMed: 23585772]

18. Schmaljohann D. Thermo- and pH-Responsive Polymers in Drug Delivery. Adv Drug Delivery Rev. 2006; 58(15):1655-1670.

19. Zhang S, Uludağ H. Nanoparticulate Systems for Growth Factor Delivery. Pharm Res. 2009; 26(7): 1561-1580. [PubMed: 19415467]

20. Mazumder Ma J, Fitzpatrick SD, Muirhead B, Sheardown H. Cell-Adhesive Thermogelling PNIPAAm/hyaluronic Acid Cell Delivery Hydrogels for Potential Application as Minimally Invasive Retinal Therapeutics. J Biomed Mater Res, Part A. 2012; 100A(7):1877-1887.

21. Kim EH, Joo MK, Bahk KH, Park MH, Chi B, Lee YM, Jeong B. Reverse Thermal Gelation of PAF-PLX-PAF Block Copolymer Aqueous Solution. Biomacromolecules. 2009; 10:2476-2481. [PubMed: 19637909]

22. Yun D, Laughter MR, Park D. A Biomimetic Reverse Thermal Gel for 3-Dimensional Neural Tissue Engineering. Austin J Biomed Eng. 2014; 1(4):1-5.

23. Zhang X, Wang F, Chu C. Thermoresponsive Hydrogel with Rapid Response Dynamics. J Mater Sci: Mater Med. 2003; 14:451-455. [PubMed: 15348449]

24. Feil H, Bae YH, Feijen J, Kim SW. Effect of Comonomer Hydrophilicity and Ionization on the Lower Critical Solution Temperature of N-Isopropylacrylamide Copolymers. Macromolecules. 1993; 26:2496-2500.

25. Roozafzoon R, Lashay A, Vasei M, Ai J, Khoshzaban A, Keshel SH, Barabadi Z, Bahrami H. Dental Pulp Stem Cells Differentiation into Retinal Ganglion-like Cells in a Three Dimensional Network. Biochem Biophys Res Commun. 2015; 457(2):154-160. [PubMed: 25543058]

26. Tanaka T, Yokoi T, Tamalu F, Watanabe SI, Nishina S, Azuma N. Generation of Retinal Ganglion Cells with Functional Axons from Human Induced Pluripotent Stem Cells. Sci Rep. 2015; 5:8344. [PubMed: 25666360] 
27. Goldberg JL, Espinosa JS, Xu Y, Davidson N, Kovacs GTA, Barres BA. Retinal Ganglion Cells Do Not Extend Axons by Default: Promotion by Neurotrophic Signaling and Electrical Activity. Neuron. 2002; 33:689-702. [PubMed: 11879647]

28. Yu DY, Cringle SJ, Balaratnasingam C, Morgan WH, Yu PK, Su EN. Retinal Ganglion Cells: Energetics, Compartmentation, Axonal Transport, Cytoskeletons and Vulnerability. Prog Retinal Eye Res. 2013; 36:217-246.

29. Kallur T, Darsalia V, Lindvall O, Kokaia Z. Human Fetal Cortical and Striatal Neural Stem Cells Generate Region-Specific Neurons In Vitro and Differentiate Extensively to Neurons After Intrastriatal Transplantation in Neonatal Rats. J Neurosci Res. 2006; 84:1630-1644. [PubMed: 17044030]

30. Bakshi A, Keck Ca, Koshkin VS, LeBold DG, Siman R, Snyder EY, McIntosh TK. CaspaseMediated Cell Death Predominates Following Engraftment of Neural Progenitor Cells into Traumatically Injured Rat Brain. Brain Res. 2005; 1065(1-2):8-19. [PubMed: 16309635]

31. Parr AM, Kulbatski I, Tator CH. Transplantation of Adult Rat Spinal Cord Stem/progenitor Cells for Spinal Cord Injury. J Neurotrauma. 2007; 24(5):835-845. [PubMed: 17518538]

32. Johnson TV, Bull ND, Martin KR. Identification of Barriers to Retinal Engraftment of Transplanted Stem Cells. Invest Ophthalmol Visual Sci. 2010; 51(2):960-970. [PubMed: 19850833]

33. Schwab E. Oligodendrocytes and CNS myelin are non-permissive substrates for neurite growth and fibroblast spreading in vitro. J Neurosci. 1988; 8:2381-2393. [PubMed: 3074158]

34. Lutolf MP, Gilbert PM, Blau HM. Designing Materials to Direct Stem-Cell Fate. Nature. 2009; 462(7272):433-441. [PubMed: 19940913]

35. Jung M, Petrausch B, Stuermer CAO. Axon-Regenerating Retinal Ganglion Cells in Adult Rats Synthesize the Cell Adhesion Molecule L1 but Not TAG-1 or SC-1. Mol Cell Neurosci. 1997; 9:116-131. [PubMed: 9245496]

36. Hersel U, Dahmen C, Kessler H. RGD Modified Polymers: Biomaterials for Stimulated Cell Adhesion and beyond. Biomaterials. 2003; 24(24):4385-4415. [PubMed: 12922151]

37. Picart C, Elkaim R, Richert L, Audoin F, Arntz Y, Da Silva Cardoso M, Schaaf P, Voegel J-C, Frisch B. Primary Cell Adhesion on RGD-Functionalized and Covalently Crosslinked Thin Polyelectrolyte Multilayer Films. Adv Funct Mater. 2005; 15(1):83-94.

38. Thompson MT, Berg MC, Tobias IS, Lichter JA, Rubner MF, Van Vliet KJ. Biochemical Functionalization of Polymeric Cell Substrata Can Alter Mechanical Compliance. Biomacromolecules. 2006; 7:1990-1995. [PubMed: 16768424]

39. Hayreh SS. Structure of the Optic Nerve. Ischemic Optic Neuropathies. 2011:456.

40. Lu Y, Franze K, Seifert G, Steinhauser C, Kirchhoff F, Wolburg H, Guck J, Janmey P, Wei E-Q, Kas J, Reichenbach A. Viscoelastic Properties of Individual Glial Cells and Neurons in the CNS. Proc Natl Acad Sci U S A. 2006; 103(47):17759-17764. [PubMed: 17093050]

41. Kador KE, Montero RB, Venugopalan P, Hertz J, Zindell AN, Valenzuela DA, Uddin MS, Lavik EB, Muller KJ, Andreopoulos FM, Goldberg JL. Biomaterials Tissue Engineering the Retinal Ganglion Cell Nerve Fiber Layer. Biomaterials. 2013; 34(17):4242-4250. [PubMed: 23489919]

42. Morgan JE. Optic Nerve Head Structure in Glaucoma: Astrocytes as Mediators of Axonal Damage. Eye (London, U K). 2000; 14:437-444. 


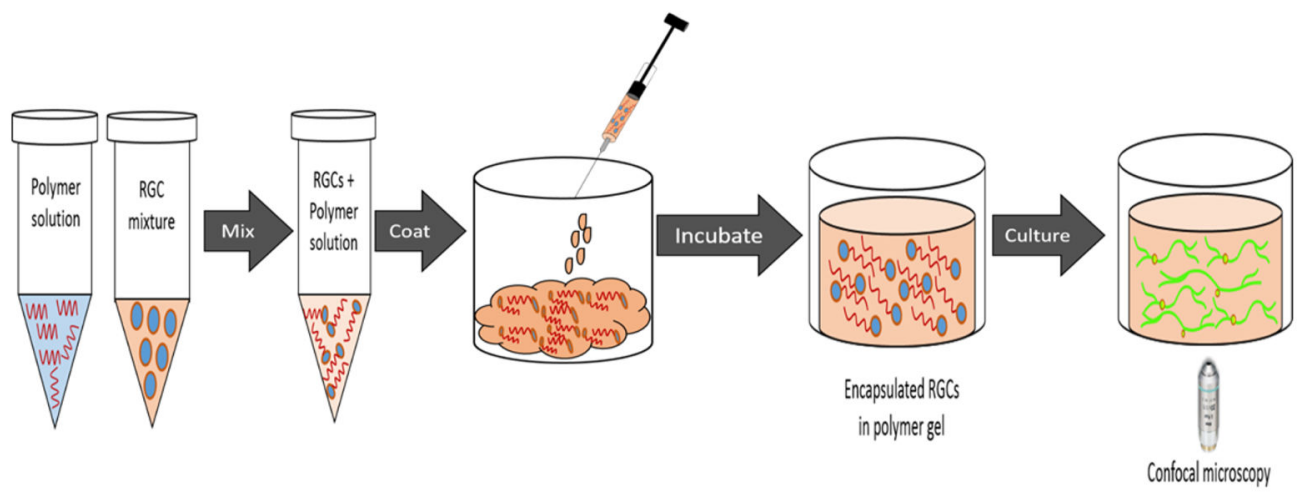

Figure 1.

Schematic showing the 3D culture process. RGCs were first mixed in with the polymer solution and loaded into a glass bottom Petri dish. After gelling at $37^{\circ} \mathrm{C}$, RGCs became encapsulated in the polymer scaffold and were cultured for future analysis. 


\section{Lower Critical Solution Temperature}

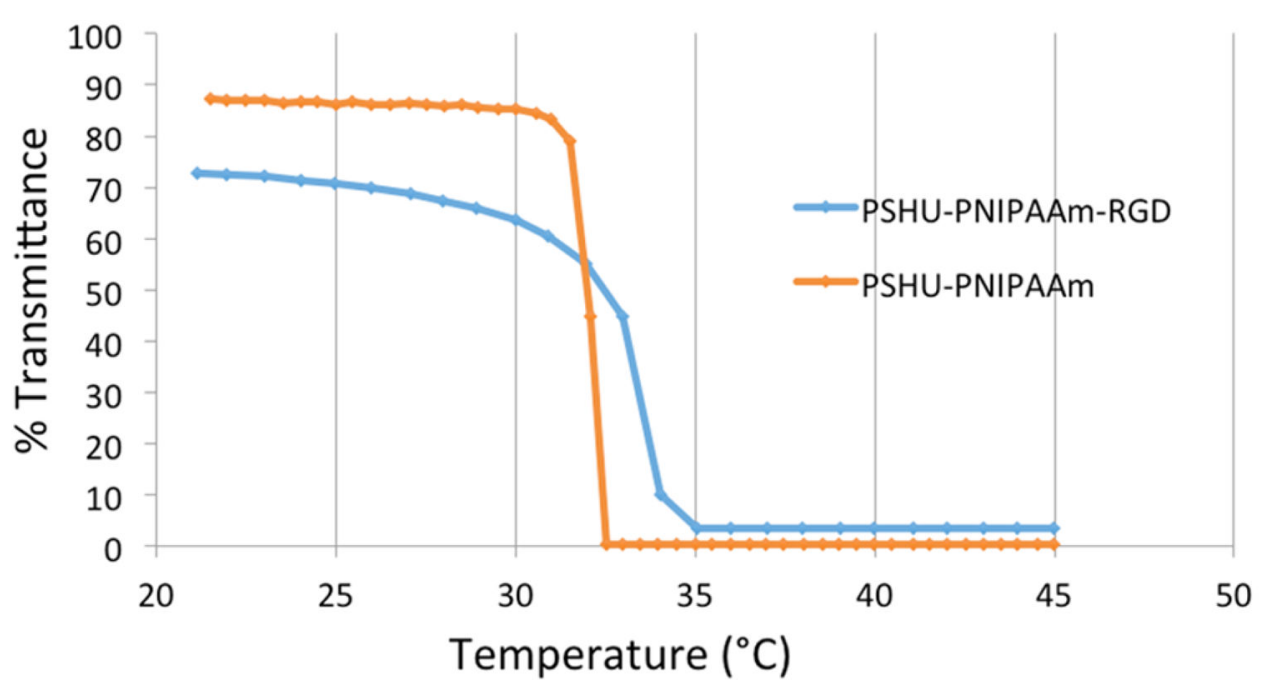

Figure 2.

Temperature-dependent phase transition of PSHU-PNIPAAm (orange) and PSHUPNIPAAm-RGD (blue). Both polymers display similar gelling temperatures, while the incorporation of the RGD peptide slightly increased the gelling time. 


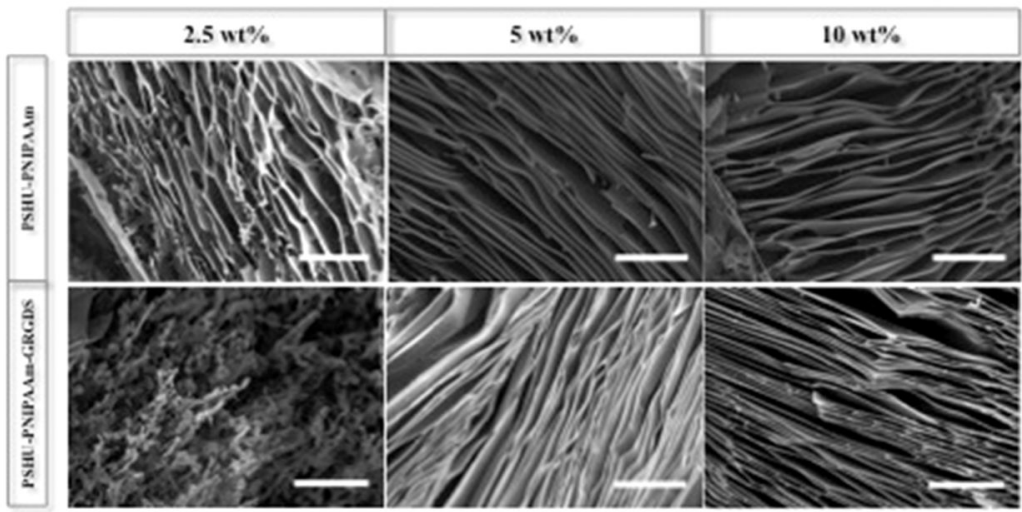

Figure 3.

Scaffold morphology. Representative SEM images of PSHU-PNIPAAm-RGD (bottom row) and PSHU-PNIPAAm (top row) at various concentrations. Concentrations above $2.5 \mathrm{wt} \%$ show a laminar sheet-like formation of the gelled polymer. The scale bar is $50 \mu \mathrm{m}$. 


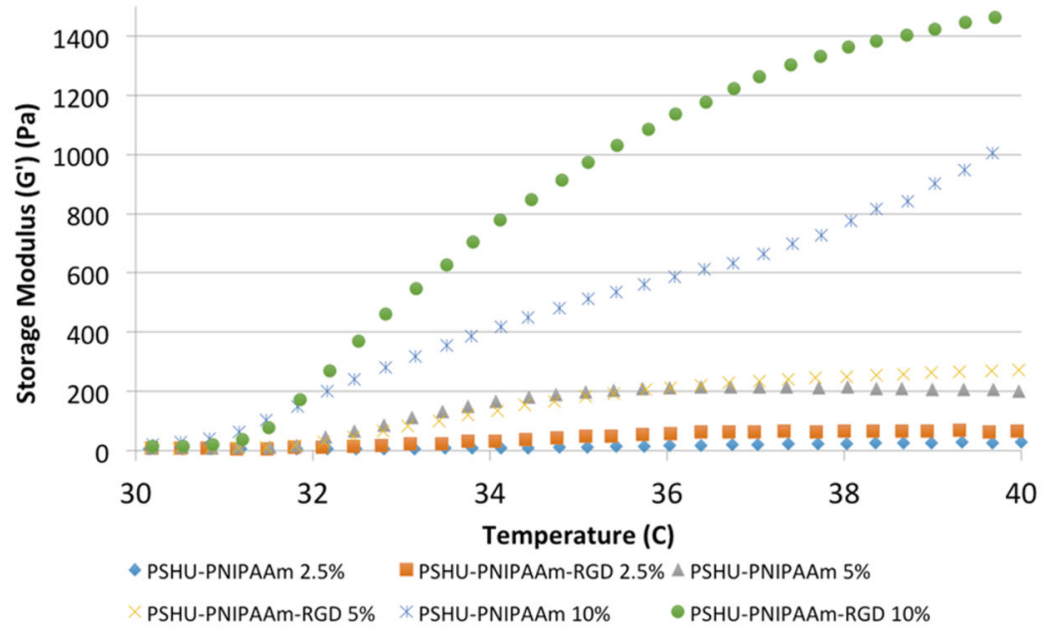

Figure 4.

Rheological properties of the polymer scaffold. The storage modulus was plotted vs temperature for various concentrations of each polymer system (PSHU-PNIPAAm-RGD and PSHU-PNIPAAm). Increasing either polymer concentration or temperature leads to an increase in the storage modulus of the material. 

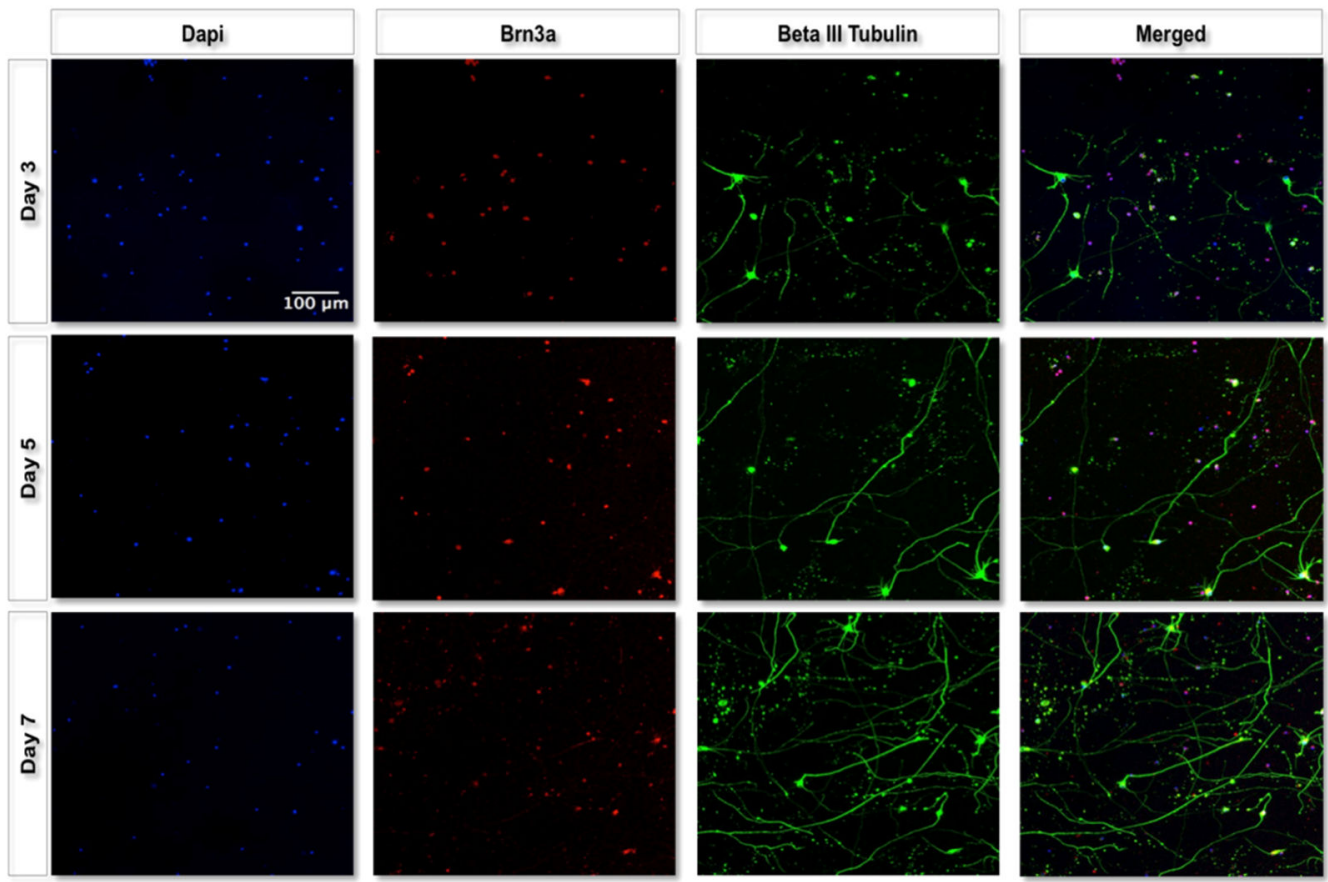

Figure 5.

Maximal intensity projections of representative 3D fluorescent images. 3D images of RGC (red) cultures in $5 \mathrm{wt} \%$ PSHU-PNIPAAm-RGD were taken using a confocal microscope after 3, 5, and 7 days in culture. RGCs (red) show long and mostly planar axon extension (green) for the 7 day culture period. 

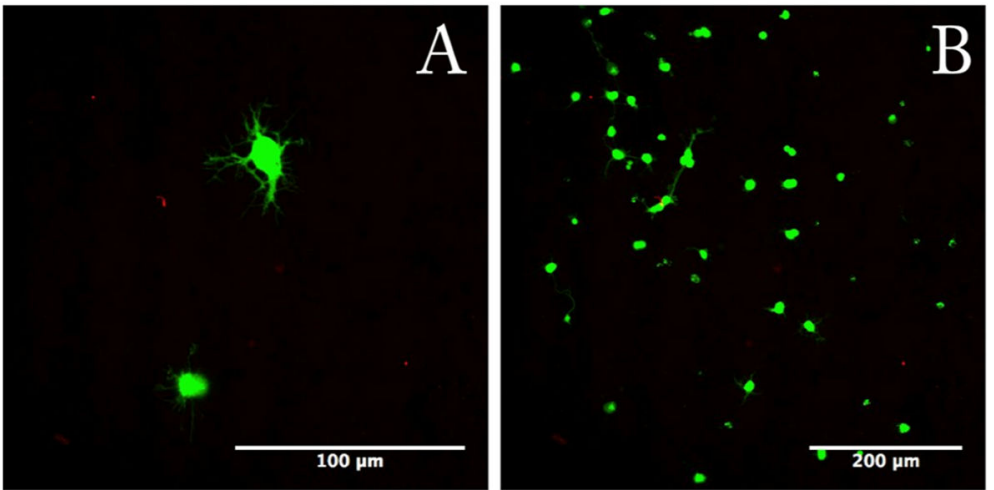

Live Calcein-AM/Dead Ethidium homodimer-1

Figure 6.

Live/dead (green/red) staining of RGC after 3 days of culture. RGCs were cultured on PDLLaminin glass coverslips and stained with live/dead (B). RGCs grown on these coverslips display a star-shaped morphology typically of RGCs grown in vitro (A). 

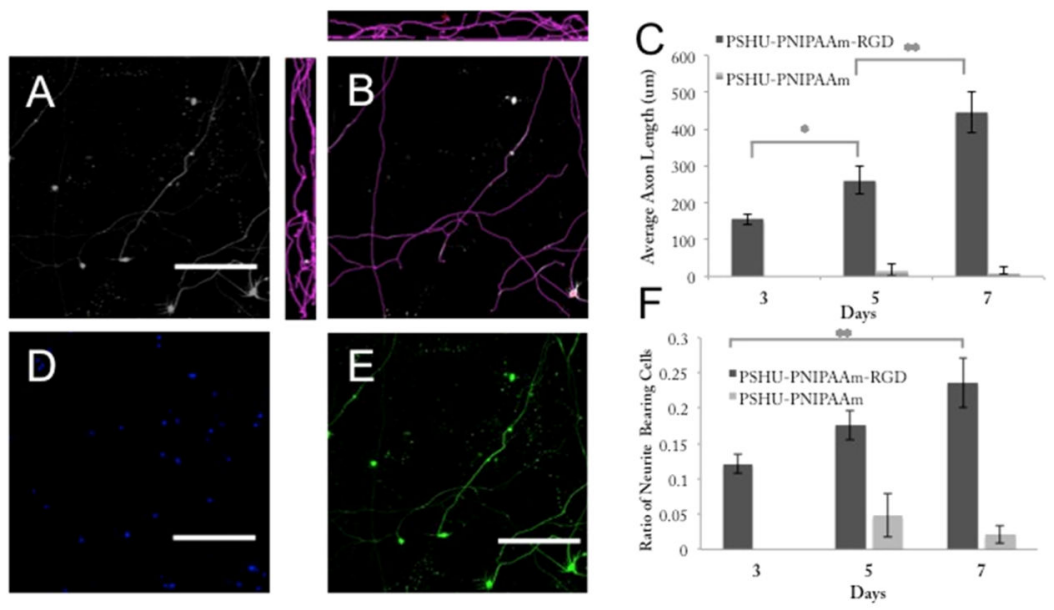

Figure 7.

Average neurite length and ratio of neurite-bearing cells. Quantification of average axon length was performed by analyzing maximal intensity images (A) in all three planes (B) for both PSHU-PNIPAAm-RGD and PSHU-PNIPAAm cultures at 3, 5, and 7 day time points (C). The ratio of neurite-bearing cells $(\mathrm{F})$ was quantified by calculating the number of cells bearing neurites in a visual frame (E) and dividing by the total number of cells within that frame (D). Numbers are plotted for both PSHU-PNIPAAm-RGD and PSHU-PNIPAAm over the 7 day culture period. Statistical significance between groups was determined by ANOVA. $* p<0.05 ; * * p<0.005$. Three images were taken from each of at least three different samples from three separate RGC isolations. The scale bar is $200 \mu \mathrm{ms}$. Day 5 cultures are shown to provide examples for quantification (A-E). 

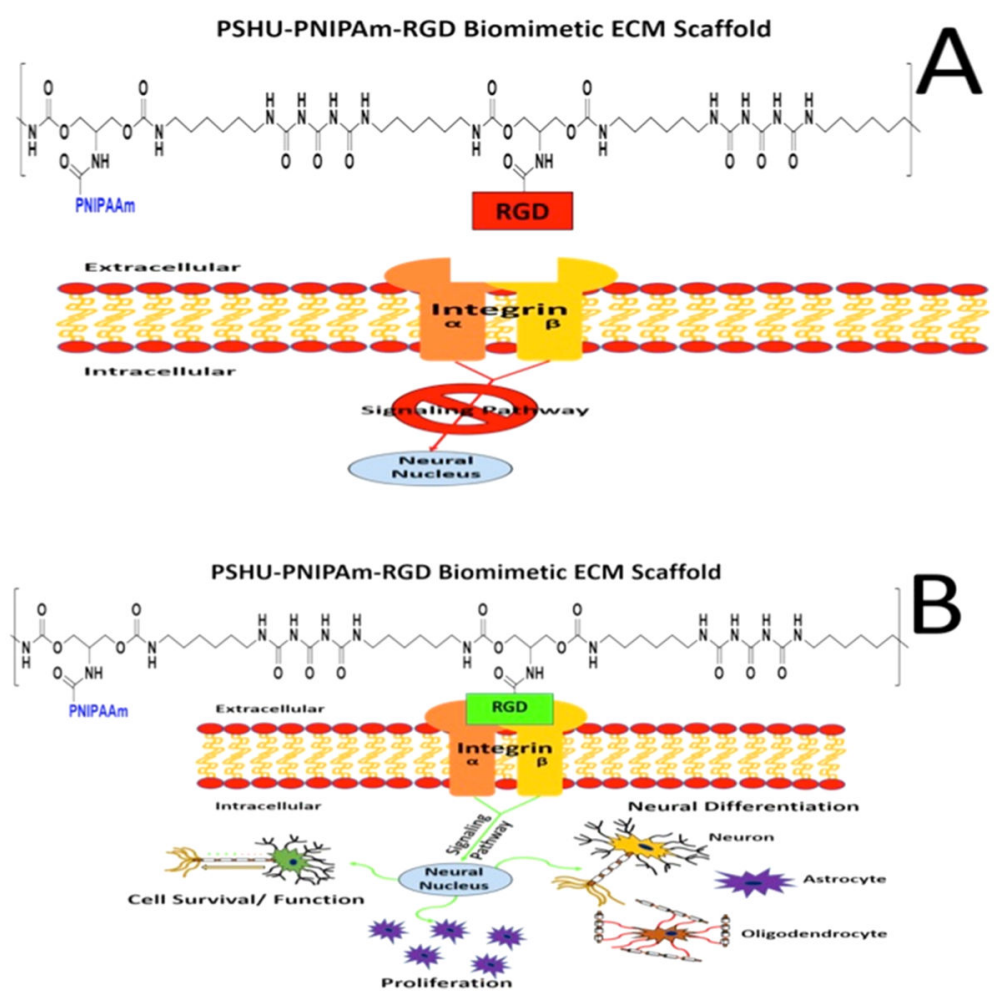

Figure 8.

Schematic showing the effects of RGD-integrin binding on cellular behavior. Binding of integrin to the RGD sequence can trigger an increase in the rate of cell survival, proliferation, and axon extension (A). The lack of integrin binding can block the signaling pathways responsible for these functions, leading to poor cell health and survival (B). 